\title{
Research on the Mechanism Innovation of Investment and Financing for Smart City Construction in Ningbo
}

\author{
Jianjun Xu \\ College of Science \& Technology Ningbo University, Ningbo, P.R.China \\ xu-jj@hotmail.com
}

Keywords: Smart City; investment and financing; Mechanism innovation

\begin{abstract}
The shortage of funds has become an important factor to limit the construction of the smart city of Ningbo. In order to meet the funds need of the construction of smart city in Ningbo, it's necessary to reform the financing mechanisms, and it has important significance for the construction of smart city of Ningbo. This paper firstly analyzes and summarizes the outstanding problems for investment and financing in the construction process of the smart city in Ningbo, then further discusses the path to realize the innovation of investment and financing mechanism, and finally puts forward the corresponding safeguard measures.
\end{abstract}

\section{Introduction}

With the advancement of the construction of Ningbo smart city, the capital shortage problems are becoming more and more prominent; the traditional investment and financing mode depending on government financial support cannot meet the need of development, so innovation of traditional investment and financing mechanism is required to fit the construction need of Ningbo smart city. In recent years, research literatures on smart city construction have sprung up, but the problems on financing of smart city construction are rarely discussed. Only a handful of research literatures emphasized the investment and financing problems of smart city (Ningbo) construction. For example, Qian Binhua (2012)[1] thought it was necessary to build fiscal policy system to support the smart city construction, and elaborated the feasibility of abating financial deficit in the process of smart city construction through public-private partnership (PPP); Zhao Quanjun and Xia Yiqun (2012) [2] insisted that the bottleneck problems of investment and financing existed in the Ningbo smart city construction were relatively obvious, and proposed to vigorously promote the innovation of investment and financing mechanism, put forth effort to solve the "investment paradox" of "no investment outside" and "few investment sources" in the smart city construction; Yan Qin, etc (2013) [3] especially emphasized the necessity of expanding financial capital investment, when discussed the composing factors of security system for smart city construction, and gradually established multiple investment and financing system which was directed by government investment, with enterprises investment as the main bodies, and social investment as important channel. The achievements have made pioneering contribution, but the systematic research results on investment and financing mechanism in (Ningbo) smart city construction have not been formed. Combined with the background of Ningbo, the study made a systematic analysis on investment and financing mechanism innovation in smart city construction, and proposed corresponding countermeasures for the reference of the relevant department.

\section{Realistic Demand for Investment and Financing Mechanism Innovation in Ningbo Smart City Construction}

Demand Analysis on Investment and Financing in Ningbo Smart City Construction. At present, the funds demand for Ningbo smart city construction mainly includes the following factors. The first is 
the fund for promoting the construction of ten smart city application systems, which focus on smart logistics, smart manufacturing, smart trade, smart energy, smart public service, smart social management, smart transportation, smart health care, smart home safety service, and smart cultural service; the second is the fund for promoting smart industry development focusing on the six smart industry bases, such as network data base, industry base for promotion of software research and development, R\&D and manufacturing base for smart equipment and product, demonstration and spreading base for smart service industry, demonstration and spreading base for smart farming, and smart corporate headquarters base; the third is the fund for accelerating the infrastructure construction of smart city, the "tri-networks integration"(the integration of telecommunication network, radio and TV network and the Internet), which will be the pilot project in Hangzhou Bay new zone, and popularized in the whole city according to the experience; the fourth is the fund for strengthening the development and utilization of smart city information resources. According to Action Plan for Accelerating Smart City Construction of Ningbo (2011-2015), the smart city construction of Ningbo will be invested with RMB 40.7 billion in five years, of which more than RMB 1 million each year are ensured to be invested, and there will be no less than RMB 500 million from municipal government annual support fund. At the same time, professional investment companies for smart construction will be set up, in order to guide more social funds for smart city construction. According to preliminary estimates, the 10 billion government investment in 10 years will leverage at least 50 billion social funds.

Existing problems in the Investment and Financing of Ningbo Smart City Construction. At present, there are lots of problems in the smart city construction from the aspects of investment and financing entity, mode, channel, platform, system, etc. In the early stage of smart city infrastructure construction, government funds take the lead while private capital investment is not enough. Specifically:

a) Decentralization of investment and financing entities and single investment mode in smart city construction. Qian Binhua (2012) [1] pointed out some existing problems, and constantly good achievements had been made from smart city infrastructure construction. Firstly, the investment and financing entities are decentralized. Secondly, the incentive to multiply investment and financing is deficient. Thirdly, the operation management efficiency is low.

b) The investment and financing channel for smart city construction may not be expedited. In the survey, Qian Binhua (2012) [1] found there were obvious bottleneck problems for investment and financing reflected by some counties (cities) in the promotion of Ningbo smart city construction. On the one hand, smart city is a newborn thing, yet the the grassroots level has inadequate understanding, the counties (cities) are unclear about the investment orientation and can't fully invest the fiscal funds arranged by municipal government; on the other hand, due to the concerns of investment risk, private capital won't or dare not invest; the investment channel and source are comparatively single, and the multiple investment and financing mechanism has not yet formed, which create the "investment paradox" of "no investment outside" and "few investment sources" coexisting in the smart city construction.

c) Financing information platform for smart city construction is expected to build, and investment risk is relatively high. In the construction of smart city, the information on different departments and industries should be shared. "However, most cities, departments and industries act of their own free will, and are unable to share information, which lead to the deadlock of "information isolated island". Wang Lida said. With all that going on, the operation efficiency of the city is decreased (Xian Zi, 2013) [4]. Compared with foreign countries, the pressure and investment risks coexist in smart city construction in China. On the one hand, the blindness of smart city construction exists, and there is a copycat construction phenomenon; on the other hand, the financing channel is single and real estate developers' venture investment accounts for certain proportion. 
d) Relevant policies and systems need to be improved in the smart city construction. In recent years, state and local governments have increased the investment on smart city construction, which has significant influence on smart city construction, while many problems also exist (Li Xianghui, 2006) [5]. The problems are: firstly, the regional policy and system reform are not coordinated, and there is no support from financial system matched with multiple investment and financing systems; secondly, the investment and financing entities and the responsibility are not clear; the efficiency is low. Thirdly, the investment behavior is not standard as it's basically decided by specific administrative leaders, and project feasibility study is bad.

\section{Implementation Path of Investment and Financing Mechanism Innovation for Ningbo Smart City}

Innovation Direction of Investment and Financing Mechanism for Ningbo Smart City. Investment and financing mechanism for smart city construction refers to the operation mechanism of investment activities and management system, which include the investment and financing channel, method, management mechanism and decision-making mechanism, etc. Therefore, the innovation should focus on broadening financing channels, financing method, financing management mechanism and financing decision-making mechanism. By actively cultivating investors for smart city investment projects, allowing the private capital, foreign capital and other capital into the smart city construction field, opening direct financing channel for smart city construction, constructing flexible and long-lasting investment and financing mechanism with multiple investment entities and mutual blending between direct financing and indirect financing, it will gradually meet the funds demand for smart application system construction, smart industry base construction, smart infrastructure construction, resident information application ability construction, smart city environment construction and so on.

Extension of Investment and Financing Channel and Method Innovation for Ningbo Smart City. a) Broaden the investment and financing channel for smart city. The sources of operation fund for smart city construction include government funding channels, the domestic indirect financing channels, the direct financing in the domestic capital market, overseas investment, enterprise investment and donations, etc. (Li Jun, 2014) [6]. The government funding channels include self-raised funds of the city, public enterprise attached, and the fund within the budget of central and local finance, policy fee approved by the state, temporary or one-off fiscal subsidy and so on. Domestic indirect financing channels include loans from domestic, commercial banks and policy banks. Smart city can use the loans from commercial banks as the source of short-term funds replenishment. Policy loan is the main source of long-term credit funds for smart city. Domestic capital markets also choose direct financing, which include shares, bonds, the introduction of social security funds, all kinds of industrial funds, insurance funds and so on. Foreign financing includes the loan from World Bank, Asian Development Bank, foreign government, etc. Business investment includes the investment from telecom enterprises, high-tech enterprises, science and technology center and private business. The selective investment in smart city construction by enterprises will be the important capital source.

b) Typical innovative investment and financing methods includes: (i) Innovation based on product payment and purchase agreement in advance, forward purchase agreement and tolling agreement. For example, "product payment" and" purchase agreement in advance" are suitable for pure profit-making project (Tian Weixing, etc. 2014) [7]. (ii) Innovation of development financing mechanism based on BOT/BOO/TOT/PPP financing modes. For example, BOT is an important way for non-government capital to invest in infrastructure field, which is suitable for developing railway traffic, railway, water plants, power plants, highways and other large infrastructure projects (Ying Wangyue, etc., 2005) [8]; (iii) Innovation of Asset-Backed Securities (ABS) and municipal bonds investment and financing 
mechanism; (iv) Mechanism innovation by setting up an industrial investment fund and franchised operation mortgage loan.

Ningbo Smart City Investment and Financing Management and Innovation for Decision-making Mechanism. a) Reform the existing financial management approach for smart city construction. First of all, improve the use efficiency of financial funds for smart city construction through centralized management. Second, take measures to manage the special funds for smart city construction by specially-assigned person, special accounts and special purpose (Liu Yi, 2009) [9]. Finally, strengthen supervision and check of the fund.

b) Build the risk guard mechanism of investment and financing funds for smart city construction. Firstly, establish complete and continuous risk management database and collect corresponding risk information by evaluating the risks of smart city construction itself and the risks of investing urban construction funds. Secondly, build a credit risk evaluation system for smart city construction. Finally, establish a risk guarantee system for construction funds.

c) Build a supervision mechanism for government investment and financing decision-making in the smart city construction. i) Establish a liability mechanism for investment and financing decision-making. First, determine the reasonable structure of the investment and financing decision-making power according to the law; second, establish liability mechanisms for investment and financing decision maker, and stipulate clearly the legal obligation and liability for decision makers who will be responsible for the decision making; third, establish compensation systems for investment and financing decision-making errors. ii) Build the triple decision-making mechanisms for investment and financing projects. The so-called triple decisions include the investment decisions, capital decisions and credit decisions.

\section{Promote Safeguarding the Investment and Financing Mechanism Innovation for Ningbo Smart City}

Unify the understanding of investment and financing mechanism innovation for smart city construction. Promote smart city construction as an important measure to build the innovation-oriented country, an important path to the transformation of an economic development model, an important goal for the development of future science and important strategy (Yan Qin, etc., 2013) ) [3]. Therefore, it is essential to fully recognize the importance and urgency of smart city construction in mind, improve the brand cognitive to smart city in all walks of life, widely carry out the propaganda and popularization of basic knowledge, work and fruits related with smart city, and win support among the people.

Strengthen the organizational leadership and coordination for investment and financing mechanism in smart city construction. Party committees and governments at all levels should accelerate the promotion of smart city construction, further strengthen organizational leadership, perfect relevant leadership system and working mechanism, then realize synergy. The municipal government should establish a leading group for Ningbo smart city construction work, and the leading group should promote and coordinate the smart city construction.

Accelerate the construction of investment and financing service platforms for smart city in local government. From the aspects of investment project approval, budget management, fund appropriation, asset revitalization and liabilities control, the relevant departments should further regulate operation of investment and financing platform company, speed up the formation of governmental fund balance "controllable scale, clear rights and liabilities, well-organized debt repayment, effective regulation" and investment and financing platform company management system (Ren Xinjian, 2012) [10]. According to the characteristics of the investment and financing in the local government investment and financing platform companies, actively promote mechanism innovation, 
optimize the investment and financing process, enhance the scientific decision-making of investment and financing, and improve the efficiency of investment and financing.

Construct the comprehensive evaluation system of investment and financing innovation for smart city construction. Establish and perfect the statistical analysis system for investment and financing mechanism innovation effect, strengthen the assessment and supervision, through the combination of appropriate appraisal and reward, fully mobilize the enthusiasm and initiative of government, industry associations and enterprises for collective action on investment and financing innovation. Establish business evaluation system, appraisal and training mechanism for enterprises participating smart city construction; set credit and financing evaluation index for financial institutions providing construction fund for smart city, and the index should be in favor of the relevant business development; the government should reward the units and individuals who seriously carry out the smart city construction.

Strengthen the experience exchange of investment and financing methods in smart city construction at home and abroad. Actively organize the Ningbo smart city construction units to participate in the international, regional economic and trade negotiation and exchange activities; introduce more cooperative projects settled in Ningbo through a series of preferential policies, attract well-known smart city construction units both at home and abroad to settle their corporate headquarters, regional headquarters or product research and development center into Ningbo, which will boost the development of Ningbo smart city.

\section{Acknowledgment}

The paper is jointly funded by project of Ningbo smart city planning standard development and research institute (grant number: 2014WT009) and project of Ningbo philosophy and social science program (grant number: G15-ZX05).

\section{References}

[1] Qian Binhua. Public-private Partnership Research on Smart City Infrastructure Construction [J]. Future and Development, 2012 (12):100-104.

[2] Zhao Quanjun. Several Problems Need to Be Deeply Researched and Solved in Accelerating the Smart City Construction [J]. San Jiang Forum, 2012 (1):8-10.

[3] Yan Qin, Zhao Quanjun, Tong Mingrong, Xia Yiqun. Theory, Frame and Element of Security System in Smart City Construction [J]. San Jiang Forum, 2013 (7):6-9.

[4] Xian Zi. Comparison of Smart City Construction at Home and Abroad[EB/OL]. http://lohas.china.com.cn/2013-08/13/content_6204808.htm.

[5] Li Xianghui, Da Kening. Innovation Research on Investment and Financing Mechanism in Small Towns [J]. Chinese market, 2006(2):146-147.

[6] Li Jun. Chinese Smart City Construction and Investment and Financing Methods in Tde of New-type Urbanization [J]. World Telecommunication, 2014 (6):39-43.

[7] Tian Weixing, He Lvmin, Shen Qihui. Study on Smart City Technical Standard System and Financial Support for the Application [J]. China Science and Technology Forum, 2014 (12):44-49.

[8] Ying Wangyue, etc. Innovation Research on Investment and Financing Mechanism in the Process of Urbanization [R]. Proceedings from Award-winning Scientific Research Projects of China Investment Association (2004-2005), 2005. 
[9] Liu Yi. Innovation Research on Investment and Financing Mechanism in the Rural Areas of China [D]. Master's thesis of Northeast Normal University, 2009.

[10]Ren Xinjian. Innovation on Investment and Financing Platform Mechanism in Local Government [J]. Scientific Development, 2012 (2):33-43. 